\title{
(6) OPEN ACCESS \\ Measuring and improving patient safety through health information technology: The Health IT Safety Framework
}

\author{
Hardeep Singh, ${ }^{1}$ Dean F Sittig ${ }^{2}$
}

\begin{abstract}
${ }^{1}$ Houston Veterans Affairs Center for Innovations in Quality, Effectiveness and Safety, Michael E. DeBakey Veterans Affairs Medical Center and Baylor College of Medicine, Houston, Texas, USA, Houston, Texas, USA

${ }^{2}$ UTHealth - Memorial Hermann Center for Healthcare Qualty and Safety, School of Biomedical Informatics, University of Texas Health Science Center, Houston, Texas, USA
\end{abstract}

\section{Correspondence to} Dr Hardeep Singh, 2002 Holcombe Blvd, 152, Houston, TX 77030, USA;

hardeeps@bcm.edu

Received 14 June 2015 Revised 5 August 2015 Accepted 20 August 2015 Published Online First 14 September 2015
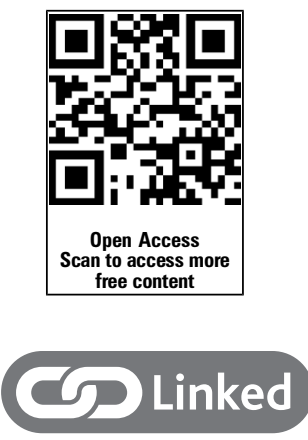

http://dx.doi.org/10.1136/ bmjqs-2015-004746

CrossMark

To cite: Singh H, Sittig DF. BMJ Qual Saf 2016;25: 226-232.

\section{ABSTRACT}

Health information technology (health IT) has potential to improve patient safety but its implementation and use has led to unintended consequences and new safety concerns. A key challenge to improving safety in health ITenabled healthcare systems is to develop valid, feasible strategies to measure safety concerns at the intersection of health IT and patient safety. In response to the fundamental conceptual and methodological gaps related to both defining and measuring health IT-related patient safety, we propose a new framework, the Health IT Safety (HITS) measurement framework, to provide a conceptual foundation for health ITrelated patient safety measurement, monitoring, and improvement. The HITS framework follows both Continuous Quality Improvement (CQI) and sociotechnical approaches and calls for new measures and measurement activities to address safety concerns in three related domains: 1) concerns that are unique and specific to technology (e.g., to address unsafe health IT related to unavailable or malfunctioning hardware or software); 2) concerns created by the failure to use health IT appropriately or by misuse of health IT (e.g. to reduce nuisance alerts in the electronic health record (EHR)), and 3) the use of health IT to monitor risks, health care processes and outcomes and identify potential safety concerns before they can harm patients (e.g. use EHR-based algorithms to identify patients at risk for medication errors or care delays). The framework proposes to integrate both retrospective and prospective measurement of HIT safety with an organization's existing clinical risk management and safety programs. It aims to facilitate organizational learning, comprehensive 360 degree assessment of HIT safety that includes vendor involvement, refinement of measurement tools and strategies, and shared responsibility to identify problems and implement solutions. A long term framework goal is to enable rigorous measurement that helps achieve the safety benefits of health IT in real-world clinical settings.

\section{INTRODUCTION}

Health information technology (health IT) has potential to improve patient safety but its implementation and use has met with unintended consequences and new safety concerns. ${ }^{1-5}$ A key challenge to improving patient safety in IT-enabled healthcare systems is to develop valid, feasible strategies to measure safety concerns at the intersection of health IT and patient safety. ${ }^{6}{ }^{7}$ For example, health IT-related adverse events, near misses and unsafe conditions are difficult to define and detect for several reasons. Because health IT is integrated with all aspects of care delivery, a wide variety of heterogeneous safety concerns can occur, often in temporally or physically separated circumstances. Moreover, causal attributions for health IT-related risks and adverse events are also difficult to identify, as they generally involve interactions of technical and non-technical factors, which are notoriously difficult to separate. ${ }^{8}$

For example, an error in the system-to-system interface between a medication order-entry module and the pharmacy inventory management system could cause a different medication to be dispensed than what was prescribed. The ordering physician may not have any indication that something is wrong, and unless the pharmacist accesses and reviews the patient's medical record and finds that the new medication was clearly not indicated for the patient, he/she has 


\section{Sociotechnical Work System* $†$}

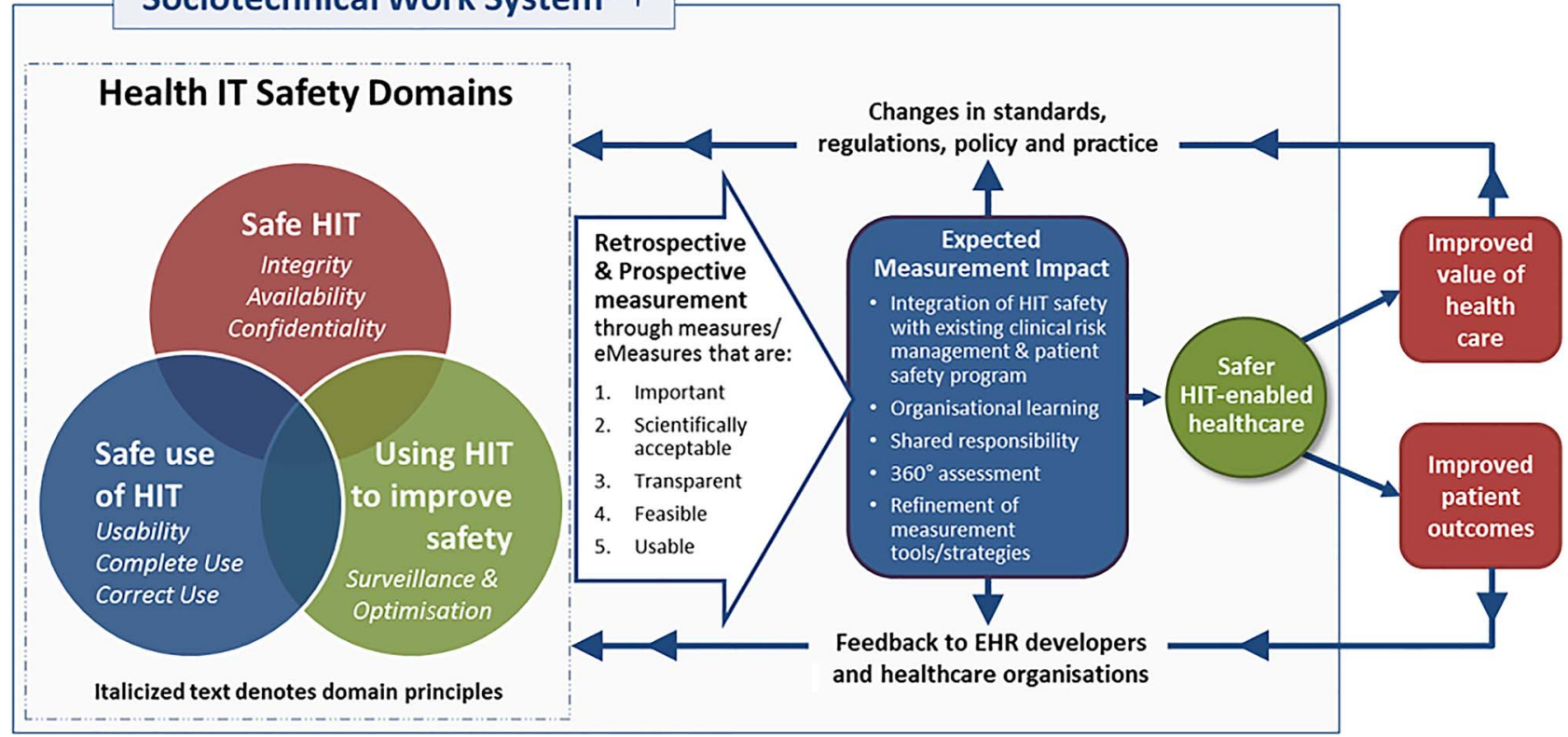

Figure 1 Health Information Technology Safety Measurement Framework (HITS Framework). *Includes eight technological and non-technological dimensions. ${ }^{\dagger}$ Includes external factors affecting measurement such as payment systems, legal factors, national quality measurement initiatives, accreditation and other policy and regulatory requirements. EHR, electronic health record.

no idea either. At present, few strategies exist to systematically detect and correct such health IT-related safety issues, and frontline clinicians and healthcare organisations (HCOs) are often unaware of recommended practices for safe health IT implementation and use. Addressing health IT-related patient safety has yet to find its place in mainstream patient safety measurement, which itself is still evolving 15 years after the landmark Institute of Medicine report on patient safety. ${ }^{9}$ Despite recent efforts to define the nature and scope of health IT-related safety concerns, ${ }^{10-12}$ the 'basic science' of measuring health IT-related patient safety remains in its infancy.

In response to the fundamental conceptual and methodological gaps related to both defining and measuring health IT-related patient safety, we developed a new framework, the health IT safety (HITS) framework, to provide a conceptual foundation for health IT-related patient safety measurement, monitoring, and improvement (figure 1).

\section{FRAMEWORK RATIONALE}

Current patient safety-oriented organisational activities do not facilitate or focus on measurement of health IT-related patient safety. Over the past few years, institutions have focused their electronic health record (EHR)-related activities on achieving meaningful use requirements, ${ }^{13}$ and less attention has been devoted to measuring patient safety concerns. However, emerging evidence suggests the need to refocus efforts. ${ }^{10}{ }^{14-16}$ Health IT is commonly deployed on a large scale, often across multiple, geographically distributed facilities, and thus the consequences of health IT-related safety concerns can rapidly affect not only a single department or institution but possibly an entire healthcare system. ${ }^{17}$ As IT-enabled patient care is rapidly becoming the norm, it is essential to (1) refine the science of measuring health IT-related patient safety (2) make health IT-related patient safety an organisational priority by securing commitment from organisational leadership and refocusing the organisation's clinical governance structure to facilitate measurement and monitoring (3) develop an environment that is conducive to detecting, fixing and learning from system vulnerabilities. We envision that the conceptual scientific foundation laid out by this framework can help overcome HITS measurement challenges, as well as position HITS at the centre of an organisation's existing patient safety-oriented activities. A long-term framework goal is to enable rigorous measurement that helps achieve the safety benefits of health IT in realworld clinical settings.

\section{OVERVIEW OF THE HITS FRAMEWORK}

The framework follows the principles of Continuous Quality Improvement, which has been defined as "a philosophy that encourages all healthcare team members to continuously ask the questions, 'How are we doing?' and 'Can we do it better?.". 18 It also addresses a third element 'how can we do better'. We describe each component of the HITS framework below.

\section{Sociotechnical work system}

The HITS framework posits that safety events must be understood within the full context of the 
'sociotechnical work system', ${ }^{19}$ which refers to the many interacting technical (hardware, software, networking infrastructure) and non-technical (clinical workflow, internal organisational policies, people, physical environment and external policies) variables that affect health IT-related patient safety (table 1).

External factors that can affect measurement include clinical productivity and legal pressures, including privacy, confidentiality and accreditation requirements; reimbursement issues, administrative demands and other confounding factors related to ongoing mandatory quality measurements. The HITS framework is set within this complex adaptive sociotechnical system. ${ }^{19}$

\section{Measurement of three overlapping domains of HITS}

The intersection of health IT and patient safety is one that involves three overlapping domains covering the lifecycle of health IT implementation and use. ${ }^{21}$ The first domain, safe health IT, pertains to addressing safety concerns that are unique and specific to technology (ie, making health IT hardware and software safe and free from malfunctions). The second domain, safe use of health IT, includes safe and appropriate use of technology by clinicians, staff and patients, as well as identifying and mitigating unsafe changes in workflows that emerge due to technology use. The third

Table 1 Sociotechnical dimensions ${ }^{19}$

\begin{tabular}{|c|c|}
\hline Dimension & Description \\
\hline Hardware and software & $\begin{array}{l}\text { Computing infrastructure used to support and } \\
\text { operate clinical applications and devices }\end{array}$ \\
\hline Clinical content & $\begin{array}{l}\text { The text, numeric data and images that } \\
\text { constitute the 'language' of clinical applications, } \\
\text { including clinical decision support }\end{array}$ \\
\hline $\begin{array}{l}\text { Human-computer } \\
\text { interface }\end{array}$ & $\begin{array}{l}\text { All aspects of technology that users can see, } \\
\text { touch or hear as they interact with it }\end{array}$ \\
\hline People & $\begin{array}{l}\text { Everyone who is involved with patient care and/ } \\
\text { or interacts in some way with healthcare } \\
\text { delivery (including technology). This would } \\
\text { include patients, clinicians and other healthcare } \\
\text { personnel, IT developers and other IT personnel, } \\
\text { informaticians }\end{array}$ \\
\hline $\begin{array}{l}\text { Workflow and } \\
\text { communication }\end{array}$ & $\begin{array}{l}\text { Processes to ensure that patient care is carried } \\
\text { out effectively, efficiently and safely }\end{array}$ \\
\hline $\begin{array}{l}\text { Internal organisational } \\
\text { features }\end{array}$ & $\begin{array}{l}\text { Policies, procedures, the physical work } \\
\text { environment and the organisational culture that } \\
\text { govern how the system is configured, who uses } \\
\text { it and where and how it is used }\end{array}$ \\
\hline $\begin{array}{l}\text { External rules and } \\
\text { regulations }\end{array}$ & $\begin{array}{l}\text { Federal or state rules (eg, CMS's Physician } \\
\text { Quality Reporting Initiative, }{ }^{20} \text { HIPAA and } \\
\text { Meaningful Use programme) and billing } \\
\text { requirements that facilitate or constrain the } \\
\text { other dimensions }\end{array}$ \\
\hline $\begin{array}{l}\text { Measurement and } \\
\text { monitoring }\end{array}$ & $\begin{array}{l}\text { Evaluating both intended and unintended } \\
\text { consequences through a variety of prospective } \\
\text { and retrospective, quantitative and qualitative } \\
\text { methods }\end{array}$ \\
\hline
\end{tabular}

HIPAA, Health Insurance Portability and Accountability Act of 1996; IT, information technology. domain, using health IT to improve safety, includes use of technology to identify and monitor patient safety events, risks and hazards and to intervene before actual harm occurs. These domains account for the range of risks and opportunities for health IT to influence patient safety in both new and established health IT-based work systems. ${ }^{21}$ Each domain is supported by principles adapted from those used in the development of the SAFER (Safety Assurance Factors for EHR Resilience) guides (table 2). ${ }^{22}$

Measurement in all three domains must involve retrospective data collection methods as well as more proactive measurement and monitoring of HITS because many errors are unknown and reporting is underutilized. ${ }^{23}$ Additional measurement methods, such as use of triggers for automated detection of health IT-related concerns and prospective methods such as proactive risk assessments could provide a more comprehensive picture of the extent and seriousness of current risks. ${ }^{24}$ Good measures should meet the criteria of being impactful (ie, important to measure and report), scientifically acceptable (reliable, valid), feasible (clinically, technically and financially), usable (easily extracted from existing EHRs) and transparent (reviewable by all stakeholders). ${ }^{25}$

\section{Expected measurement impact}

The complex and multifaceted nature of health IT-related safety risks necessitates the co-operation of multiple stakeholders, including healthcare providers, patient safety professionals and EHR vendors, to collaboratively address safety concerns and develop tools and strategies to optimise the safety of health IT. However, health IT-related safety is not currently integrated with most HCOs' patient safety programmes. $^{8}{ }^{26}$ Improved measurement is needed to create feedback for organisational learning, ${ }^{27} 28$ which in turn should lead to development of more refined measurement tools, clear definitions and rigorous assessments of the types of safety concerns the organisation should focus on. It would also lead to prioritising and implementing best practices related to HITS, enacting plans to maintain safety practices already in place and dedicating the required financial and human resources to make necessary improvements.

Measurement is critically dependent on a heterogeneous group of people, including those who are more technically oriented (eg, EHR developers, user interface designers, database administrators, hardware and networking infrastructure-related personnel) as well as those focused on healthcare delivery systems (eg, clinical medicine, quality improvement, organisational change, risk management and patient safety). Creating an environment in which these individuals with widely varying backgrounds can work together on measurement and learning in a collegial manner is no small task. The framework thus posits that all of these people share responsibility for improvement, which 
Table 2 Health IT safety domains (Adapted from reference 39)

\begin{tabular}{ll}
\hline Level & Principles adapted from those used in the development of the SAFER guides \\
\hline $\begin{array}{l}\text { Domain 1 } \\
\text { Safe health IT: address safety concerns unique to }\end{array}$ & $\begin{array}{l}\text { Data availability-Health IT is accessible and usable upon demand by authorised individuals. } \\
\text { Data integrity - Health IT data or information is accurate and created appropriately and has not } \\
\text { technology }\end{array}$ \\
$\begin{array}{l}\text { been altered or destroyed in an unauthorised manner. } \\
\text { Data confidentiality - Health IT data or information is only available or disclosed to authorised } \\
\text { persons or processes. }\end{array}$ \\
$\begin{array}{l}\text { Using health IT safely: optimise the safe use of } \\
\text { technology }\end{array}$ \\
$\begin{array}{l}\text { Complete/correct health IT use-Health IT features and functionality are implemented and used as } \\
\text { intended. }\end{array}$ \\
$\begin{array}{l}\text { Health IT system usability-Health IT features and functionality are designed and implemented so } \\
\text { that they can be used effectively, efficiently and to the satisfaction of the intended users to } \\
\text { Monitoring safety: use technology to monitor and } 3 \\
\text { improve patient safety }\end{array}$ & $\begin{array}{l}\text { Surveillance and optimisation-As part of ongoing quality assurance and performance } \\
\text { improvement, mechanisms are in place to monitor, detect and report on the safety and safe use of } \\
\text { health IT, and leverage health IT to reduce patient harm and improve safety. }\end{array}$
\end{tabular}

IT, information technology; SAFER, Safety Assurance Factors for EHR Resilience.

means the $\mathrm{HCO}$ and its various internal and external IT partners, including EHR vendors, must share the responsibility of safety. ${ }^{12}$ For example, many EHRs now calculate and display a 'falls risk assessment score' for patients based on age, medications, clinical condition and recent procedures. If there is an error in this calculation or erroneous data creeps into the patient's EHR, this score will be incorrect. As a result, the nursing staff, increasingly dependent on these computer-based reminders, might not take appropriate fall prevention precautions leading to a preventable adverse event. The EHR and those responsible for its content also have a role in addressing this problem. Organisational learning would be fostered by sharing responsibility for safety with the EHR vendors and ensuring that different external stakeholders, such as EHR vendors, clinical knowledge suppliers or IT infrastructure providers, achieve a shared understanding of safe practices.

While recent analyses of retrospective reports confirm safety problems, they tend to provide a narrow and technical view of the picture, rather than one through a sociotechnical lens. Moreover, it is notable that none of these data have been collected from vendors. To advance the 'basic science' of health IT-related safety, the HITS framework suggests a 360-degree approach that includes both sociotechnical thinking and vendor involvement to enable systemwide learning. It is unclear how EHR vendors are obtaining and using feedback about the effects of their systems on patient safety. Given the increasing number of EHR vendors, ensuring they are included in health IT-related patient safety initiatives is critical.

Recent efforts have been made to facilitate the reporting of health IT-related incidents, ${ }^{29}{ }^{30}$ but little is known about how to analyse this data to generate actionable findings. ${ }^{26}$ Closely integrating HITS with an organisation's existing clinical risk management and patient safety programmes could help achieve that. These programmes could ensure that data from existing safety events are aggregated and used to identify common health IT-related unsafe conditions, provide recommendations to mitigate risks and follow-up with responsible stakeholders to ensure that recommendations are actually implemented.

All of these measurement impacts would help create a culture of health IT-related patient safety and inform safer IT-enabled healthcare.

\section{USE OF THE FRAMEWORK TO OVERCOME CHALLENGES OF REAL-WORLD MEASUREMENT}

In this section, we discuss how various components of the HITS framework can work together and help overcome key challenges in advancing measurement of health IT-related safety. We also outline some key necessities and assumptions for the framework to function for this purpose.

\section{Uncover hidden HIT safety risks}

Health IT operations are not visible to EHR users and without a basic HITS measurement system in place, it is unlikely that health IT-related concerns will be captured easily. The HITS framework presupposes that HCOs will need to obtain authority and resources from organisational leadership and their firm commitment to measurement and reporting in all three domains of HITS. This new approach is needed because users are often unaware of the origins of safety concerns or how health IT was involved. ${ }^{31}$ 'Hidden' safety issues ${ }^{32}$ carry the potential to affect many patients. For example, in one study, several systematic errors resulted in missed follow-up of abnormal laboratory test results, ${ }^{33}$ including problems with the test ordering and reporting workflow and problems with the configuration of the system that should have automatically notified the appropriate provider of the abnormal result. As a result, several providers did not receive timely notification of their patients' abnormal test results. This error remained unknown for several months and affected a large number of tests. 
HITS framework also assumes that HCOs will modify their existing patient safety structures and processes to incorporate the unique skill mix needed for comprehensive, three-domain HITS measurement. For example, HCOs might need to use informaticians or clinicians trained in the newly created subspecialty of clinical informatics or a multidisciplinary oversight committee to help identify risks, prioritise interventions and review IT-related solutions. ${ }^{34} 35$ They might also create multidisciplinary EHR safety teams with human factors and informatics expertise to investigate safety events with potential 'health IT involvement'. These teams could work within the protections of patient safety organisations during investigations and solution development and be integrated with an HCO's existing risk management infrastructure. ${ }^{36}$

\section{Facilitate organisational preparedness}

HCOs using health IT would first need to rigorously assess their measurement readiness in all three domains of HITS and consider how HITS is integrated within their existing patient safety infrastructure. ${ }^{37}$ This would require determining how health IT/EHRs are involved in safety events and what types of changes have been made based on this data. Risk managers and other quality personnel would need to become aware of red flags for health IT-related safety issues. ${ }^{38}$ They could also consider conducting or participating in proactive risk assessments using SAFER guides $^{22} 39$ and integrate these activities within their existing patient safety programmes.

\section{ADVANCE CURRENT MEASUREMENT METHODS}

Although it is well established that health IT can introduce new types of errors, ${ }^{2} 14 \quad 15 \quad 40-42$ comprehensive data on IT-related safety events are lacking ${ }^{11}{ }^{14}$ and most current data comes from reporting of safety events. Voluntary reporting alone detects only a small proportion of problems and often neglects latent errors and near-misses that could point to important safety issues. ${ }^{11} 43$ Moreover, few organisations are reporting health IT or EHR-related safety issues. Thus, alternative approaches to data collection need to be used to capture and respond appropriately to the full scope of health IT-related safety risks. HCOs will also need to consider additional methods of measurement beyond reporting, such as the use of automated triggers to detect wrong patient orders, ${ }^{24}$ helpdesk logs, ${ }^{10}$ triggers for ordering recovery medications (naloxone outside the operating room), ${ }_{47}^{44}$ provocative testing ${ }^{45}$ or real-time observations ${ }^{46} 47$ and feedback from users. They will also need measures to address certain framework components, such as what type of turnaround time exists for resolving vendor-reported EHR safety concerns (for shared responsibility). Better measurement will also promote the development of a comprehensive taxonomy of HITS concerns. ${ }^{10} 141648$
Identify top priorities for measure development

Beyond HCO-level use, HITS framework could provide a conceptual foundation for initiatives currently underway to advance measurement of HITS. For example, the National Quality Forum is currently developing a comprehensive approach to assess HITS measurement and conducting a measure gap analysis. The framework could help identify priorities for measure development in each of the HITS domains and their respective principles outlined in table 2 . Measurement was also emphasised recently by the Roadmap for the Federal Health IT Safety Center in the USA, ${ }^{12}{ }^{49}$ which is expected to be operationalised within the authorities of the Office of the National Coordinator for Health Information Technology and the Agency for Healthcare Research and Quality.

In conclusion, the HITS framework helps conceptualise patient safety related to health IT, both in terms of risks emanating from health IT and its uses and how health IT might be harnessed to enhance patient safety. A key risk in any new measurement initiative, which this framework could help overcome, is leaving out one or more essential concepts that are fundamental to improvement initiatives, which could lead the initiative to fail. Although careful definition and eventual operationalisation of the many concepts necessary to provide a full picture of health IT-related patient safety will be challenging, the HITS framework can be used to provide a foundation for efforts to advance measurement and help identify priorities for measure development. The framework proposes to integrate both retrospective and prospective measurement of HITS within an organisation's existing clinical risk management and safety programme and aims to facilitate organisational learning, comprehensive 360-degree assessment of HITS, refinement of measurement tools and strategies and shared responsibility to identify problems and implement solutions. This approach would enable us to achieve the safety benefits of health IT in real-world clinical settings.

Twitter Follow Hardeep Singh at @HardeepSinghMD and Dean Sittig at@DeanSittig

Acknowledgements We thank Andrea Bradford, PhD, for her review and editorial assistance with this manuscript.

Contributors HS and DFS have significantly contributed to the planning, conduct and reporting of the work reported in this article. Concept and design; analysis and interpretation; drafting and revision of the manuscript; administrative and technical support: HS, DFS.

Funding HS is supported by the VA Health Services Research and Development Service (CRE 12-033; Presidential Early Career Award for Scientists and Engineers USA 14-274), the VA National Center for Patient Safety and the Agency for Health Care Research and Quality (R01HS022087). This work is supported in part by the Houston VA HSR\&D Center for Innovations in Quality, Effectiveness and Safety (CIN 13-413). HS presented the HITS framework to the National Quality Forum Health IT Safety Committee on 16 February 2015.

Competing interests None declared. 
Provenance and peer review Not commissioned; externally peer reviewed.

Open Access This is an Open Access article distributed in accordance with the Creative Commons Attribution Non Commercial (CC BY-NC 4.0) license, which permits others to distribute, remix, adapt, build upon this work noncommercially, and license their derivative works on different terms, provided the original work is properly cited and the use is non-commercial. See: http://creativecommons.org/licenses/by$\mathrm{nc} / 4.0 /$

\section{REFERENCES}

1 Koppel R, Metlay JP, Cohen A, et al. Role of computerized physician order entry systems in facilitating medication errors. JAMA 2005;293:1197-203.

2 Harrington L, Kennerly D, Johnson C. Safety issues related to the electronic medical record (EMR): synthesis of the literature from the last decade, 2000-2009. J Healthc Manag 2011;56:31-43; discussion 43-4.

3 Magrabi F, Ong MS, Runciman W, et al. An analysis of computer-related patient safety incidents to inform the development of a classification. J Am Med Inform Assoc 2010;17:663-70.

4 Magrabi F, Aarts J, Nohr C, et al. A comparative review of patient safety initiatives for national health information technology. Int J Med Inform 2013;82:e139-48.

5 ECRI Institute PSO Deep Dive: Health Information Technology. ECRI Institute PSO. 2012 (cited 14 Mar 2014). https://www.ecri.org/EmailResources/PSRQ/ECRI_Institute_ PSO_Deep\%20Dive_HIT_TOC.pdf

6 Veterans Health Administration. VHA National Patient Safety Improvement Handbook. VHA Handbook 1050.1. 3-4-2011. Washington DC. 9-10-2013.

7 Clancy CM. Common formats allow uniform collection and reporting of patient safety data by patient safety organizations. Am J Med Qual 2010;25:73-5.

8 Walker JM, Carayon P, Leveson N, et al. EHR safety: the way forward to safe and effective systems. J Am Med Inform Assoc 2008;15:272-7.

9 To err is human: Building a safer health system. Kohn LT, Corrigan JM, Donaldson MS, eds. Washington, D.C., National Academy Press. 2000.

10 Meeks DW, Smith MW, Taylor L, et al. An analysis of electronic health record-related patient safety concerns. J Am Med Inform Assoc 2014;21:1053-9.

11 Sittig DF, Singh H. Defining health information technology-related errors: new developments since to err is human. Arch Intern Med 2011;171:1281-4.

12 Sittig DF, Classen DC, Singh H. Patient safety goals for the proposed Federal Health Information Technology Safety Center. J Am Med Inform Assoc 2015;22:472-8.

13 Wright A, Henkin S, Feblowitz J, et al. Early results of the meaningful use program for electronic health records. $\mathrm{N} \mathrm{Engl} \mathrm{J}$ Med 2013;368:779-80.

14 Magrabi F, Ong MS, Runciman W, et al. Using FDA reports to inform a classification for health information technology safety problems. J Am Med Inform Assoc 2012;19:45-53.

15 Magrabi F, Baker M, Sinha I, et al. Clinical safety of England's national programme for IT: a retrospective analysis of all reported safety events 2005 to 2011. Int J Med Inform 2015;84:198-206.

16 Patient Safety Advisory Group. Safe use of health information technology—Sentinel Event Alert \#54. The Joint Commission. 2015. http://www.jointcommission.org/assets/1/18/SEA_54.pdf
17 National Public Radio. Anti-virus program update wreaks havoc with PCs. www npr org. 2010 (cited 23 Mar 2014 A. D.). http://www.npr.org/templates/story/story.php? storyId $=126168997 \& s c=17 \& \mathrm{f}=1001$

18 Health Information Technology Research Center (HITRC). Continuous Quality Improvement (CQI) Strategies to Optimize your Practice-Primer. The National Learning Consortium (NLC). 2013.

19 Sittig DF, Singh H. A new sociotechnical model for studying health information technology in complex adaptive healthcare systems. Qual Saf Health Care 2010;19(Suppl 3):i68-74.

20 Stulberg J. The physician quality reporting initiative-a gateway to pay for performance: what every health care professional should know. Qual Manag Health Care 2008;17:2-8.

21 Sittig DF, Singh $\mathrm{H}$. Electronic health records and national patient-safety goals. N Engl J Med 2012;367:1854-60.

22 Safety Assurance Factors for EHR Resilience (SAFER) Guides. Office of the National Coordinator for Health Information Technology (ONC). 2014 (cited 5 Aug 2014). http://www. healthit.gov/safer/safer-guides

23 Thomas EJ, Petersen LA. Measuring errors and adverse events in health care. J Gen Intern Med 2003;18:61-7.

24 Adelman JS, Kalkut GE, Schechter CB, et al. Understanding and preventing wrong-patient electronic orders: a randomized controlled trial. J Am Med Inform Assoc 2013;20:305-10.

25 National Quality Forum (NQF). National Voluntary Consensus Standards for Public Reporting of Patient Safety Event Information. A Consensus Report. Washington DC, 2010, NQF. 6-11-0015.

26 Menon S, Singh H, Meyer AN, et al. Electronic health record-related safety concerns: a cross-sectional survey. J Healthc Risk Manag 2014;34:14-26.

27 Weick KE, Sutcliffe KM, Obstfeld D. Organizing for high reliability: Processes of collective mindfulness. Res Organ Behav 1999;21:81-123.

28 Singh H, Sittig DF. Advancing the science of measurement of diagnostic errors in healthcare: the Safer Dx framework. BMJ Qual Saf 2015;24:103-10.

29 PDR Secure. EHR Safety Event Reporting Service. http:// ehrevent.org/. 2010 (cited 13 May 2011). http://www.ehrevent. org/

30 Mosquera M. AHRQ tests tool identify, report health IT hazards. 2011 (cited 7 Oct 2011). http://govhealthit.com/news/ ahrq-tests-tool-identify-and-report-health-it-hazards

31 Walker JM, Hassol A, Bradshaw B, et al. Health IT Hazard Manager Beta-Test: Final Report (Prepared by Abt Associates and Geisinger Health System, under Contract No. HHSA290200600011i, \#14). 12-0058-EF. Rockville, MD, Agency for Health care Research and Quality, 2012. 3-14-2014.

32 Reason J. Human error: models and management. BMJ 2000;320:768-70.

33 Singh H, Wilson L, Petersen L, et al. Improving follow-up of abnormal cancer screens using electronic health records: trust but verify test result communication. BMC Med Inform Decis Mak 2009;9.

34 Gardner RM, Overhage JM, Steen EB, et al. Core content for the subspecialty of clinical informatics. J Am Med Inform Assoc 2009;16:153-7.

35 Detmer DE, Shortliffe EH. Clinical informatics: prospects for a new medical subspecialty. JAMA 2014;311:2067-8.

36 Howard J, Levy F, Mareiniss DP, et al. New legal protections for reporting patient errors under the Patient Safety and 


\section{Viewpoint}

Quality Improvement Act: a review of the medical literature and analysis. J Patient Saf 2010;6:147-52.

37 Vincent C, Burnett S, Carthey J. The measurement and monitoring of safety. London: The Health Foundation, 2013. 8-27-2014.

38 Sittig DF, Singh H. A red-flag-based approach to risk management of EHR-related safety concerns. J Healthc Risk Manag 2013;33:21-6.

39 Sittig DF, Ash JS, Singh H. The SAFER guides: empowering organizations to improve the safety and effectiveness of electronic health records. Am J Manag Care 2014;20: 418-23.

40 Myers RB, Jones SL, Sittig DF. Review of reported clinical information system adverse events in US Food and Drug Administration databases. Appl Clin Inf 2011;2:63-74.

41 Institute of Medicine. Health IT and Patient Safety: Building Safer Care. 2011.

42 Warm D, Edwards P. Classifying health information technology patient safety related incidents - an approach used in Wales. Appl Clin Inform 2012;3:248-57.

43 Koppel R. Monitoring and evaluating the use of electronic health records. JAMA 2010;303:1918-19.
44 Stockwell DC, Bisarya H, Classen DC, et al. Development of an electronic pediatric all-cause harm measurement tool using a modified Delphi method. J Patient Saf 2014 doi:10.1097/PTS. 0000000000000139

45 Schiff GD, Amato MG, Eguale T, et al. Computerised physician order entry-related medication errors: analysis of reported errors and vulnerability testing of current systems. BMJ Qual Saf 2015;24:264-71.

46 Westbrook JI, Woods A. Development and testing of an observational method for detecting medication administration errors using information technology. Stud Health Technol Inform 2009;146:429-33.

47 Westbrook JI, Woods A, Rob MI, et al. Association of interruptions with an increased risk and severity of medication administration errors. Arch Intern Med 2010;170:683-90.

48 Ruder DB. Malpractice claims analysis confirms risks in EHRs. Patient Saf Qual Healthc 2014;11:20-3.

49 RTI International Roadmap Task Force. Health IT Safety Center Roadmap. Prepared for the Office of the National Coordinator for Health Information Technology (ONC). RTI International. 2015. http://www.healthitsafety.org/uploads/4/3/ 6/4/43647387/roadmap.pdf 